\title{
Discrete element modeling of masonry structures: Validation and application
}

\author{
Bora Pulatsu $^{* 1}$, Eduardo M. Bretas ${ }^{2 a}$ and Paulo B. Lourenço ${ }^{3 b}$ \\ ${ }^{1}$ Institute for Sustainability and Innovation in Structural Engineering, University of Minho, Guimarães, Portugal \\ ${ }^{2}$ Department of Infrastructure, Materials and Structures, Northern Research Institute, Narvik, Norway \\ ${ }^{3}$ Institute for Sustainability and Innovation in Structural Engineering, University of Minho, Guimarães, Portugal
}

\begin{abstract}
The failure mechanism and maximum collapse load of masonry structures may change significantly under static and dynamic excitations depending on their internal arrangement and material properties. Hence, it is important to understand correctly the nonlinear behavior of masonry structures in order to adequately assess their safety and propose efficient strengthening measures, especially for historical constructions. The discrete element method (DEM) can play an important role in these studies. This paper discusses possible collapse mechanisms and provides a set of parametric analyses by considering the influence of material properties and cross section morphologies on the out of plane strength of masonry walls. Detailed modeling of masonry structures may affect their mechanical strength and displacement capacity. In particular, the structural behavior of stacked and rubble masonry walls, portal frames, simple combinations of masonry piers and arches, and a real structure is discussed using DEM. It is further demonstrated that this structural analysis tool allows obtaining excellent results in the description of the nonlinear behavior of masonry structures.
\end{abstract}

Keywords: discrete element method (DEM); masonry structures

\section{Introduction}

Masonry has a remarkable place in the construction field, dating back more than 10,000 years ago (Lourenço 2009). However, due to developments in concrete and steel, a noticeable decrease is observed in masonry since the late $19^{\text {th }}$ century. Still, safety and seismic assessment of masonry constructions, especially historical structures, is an important research field in structural engineering. Hence, in this paper, the simulation of the failure of masonry structures under pushover analysis, i.e. lateral loading proportional to the inertial forces occurring in an earthquake, are comprehensively examined, which is useful for the seismic assessment and evaluation of the performance of structures with large inelastic deformation (Krawinkler 1996). The common failure mechanisms of masonry structures subjected to out of plane loading is rigid overturning and partially or fully separation of external leaves. To understand the observed collapse mechanisms, different types of scenarios are prepared considering numerous masonry wall cross sections and

*MSc, E-mail: bpulatsu2@unl.edu

${ }^{a}$ Corresponding author, Ph.D., E-mail: eduardo.bretas@ norut.no

${ }^{\mathrm{b}}$ Full Professor, E-mail: pbl@civil.uminho.pt 
structures, with varying geometrical and material properties.

First, the construction technique and quality of masonry walls, so called workmanship, is considered. A severe decrease of capacity in case of poor workmanship or lack of through stones, crossing the wall, is found. A parametric study is also performed assuming different material properties. The results of strength deterioration and failure of masonry walls is captured by uniformly distributed lateral loads, applied in an incremental fashion. The masonry walls are modeled by deformable distinct blocks and joints using a Discrete Element (DE) code. In fact, DE models fit well the composite nature of masonry, which is made by discrete units bound by joints, which may be dried or mortared. The mechanical behavior of units and corresponding failure mechanisms including joint sliding, joint partial or total separation, and joint large deformations are possible (Lemos 2007). Here, besides the walls, also portal frames, simple combinations of masonry piers and arches, and a real case study of a minaret in India are addressed. It is shown that Discrete Element Modelling (DEM) of masonry structures allows obtaining adequate structural failure mechanisms and loads in the context of seismic analysis, meaning that it is a powerful tool available to researchers and practitioners.

\section{Definition of masonry cross section typologies}

During the process of structural analysis of masonry structures, classifying the cross sections is a starting point to discuss their behavior and mechanical properties (Isfeld and Shrive 2015). Several attempts have been made to catalogue masonry walls in homogeneous groups or typologies (Binda et al. 2000). The main challenge is the complex nature of the masonry itself, which can affect its mechanical, physical and chemical properties. However, the mechanical behavior of masonry structures greatly depends on construction technology and structural details, which is the main motivation here. A masonry catalogue for the stone and brick masonry cross sections has been proposed in (Binda et al. 2005), taking into account the percentage of units, mortar and voids, the presence of connections and headers (or through stones), and masonry bond. Still, it is important to note that categorizing historical masonry is a challenging work due its heterogeneity, unlike modern masonry. Moreover, difficulties in the numerical analysis of masonry walls increase with the in-plane or in-height irregularity of the structure and the complex geometry of the wall cross sections. Here, two different masonry walls are taken into account, namely stacked and rubble masonry walls.

First, five different stack bonded regular masonry wall cross sections are defined, assumed as possible types. The pattern of regular stone units is changed according to the size of units, as shown in Fig. 1. The same thickness and height is considered for all masonry wall cross sections to eliminate the influence of aspect ratio. The thickness and height are $0.5 \mathrm{~m}$ and $3.5 \mathrm{~m}$, respectively, or a ratio of thickness to height of 1:7. It is important to note that, depending on the cross section, starting from the simplest stacked wall, cross section 1, to more sophisticated models with interlocking in a single leaf wall, e.g. cross section 5, different out of plane behavior is expected. 


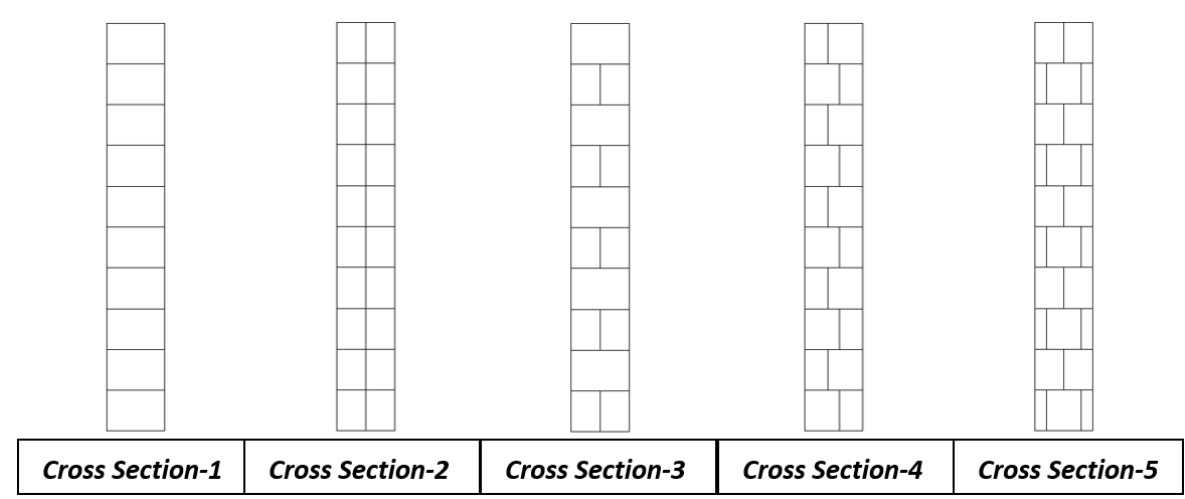

Fig. 1 Adopted stack bonded masonry walls

Then, different irregular (or rubble) masonry wall sections including single leaf and three leaves are prepared; see Fig. 2, as representative of traditional stone masonry walls. The single leaf masonry sections, shown in Fig. 2(a)-(c), are inspired by good quality stone walls, where the material is widely available and can be easily cut (typically relatively thin walls, e.g. up to $0.40 \mathrm{~m}$ ). The three leaves rubble masonry walls are representative cross sections in many urban areas, vernacular construction and also large monumental walls, as shown in Fig. 2(d)-(e).

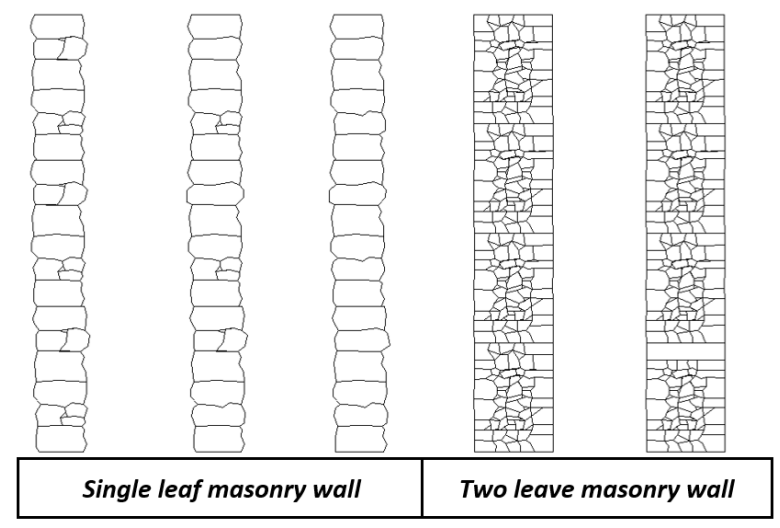

(a)

(b)

(c)

(d)

(e)

Fig. 2 Adopted irregular bonded masonry walls: (a-c) Single leave rubble masonry cross sections including different type of stone arrangements, (d) three leave wall without through stone, (e) three leave wall with through stone.

\section{Numerical modelling of masonry walls}

It is well known that unreinforced masonry walls are susceptible to failure when subjected to out of plane loads, either concentrated or distributed. From the beginning of the $15^{\text {th }}$ century, out of plane performance of masonry structures under seismic action is considered as the most critical issue for masonry walls (Ferreira et al. 2014). In literature, there are extensive research on 
advanced numerical modeling and analysis of historic masonry structures since some decades (Roca et. al. 2010, Giamundo et. al. 2014 and Asteris et. al. 2015). However, this is still a challenge for engineers, in case of unreinforced masonry, depending on availability of data and level of accuracy required (Lourenço 2002).

The two main numerical strategies of masonry structures are macro (continuum mechanics models) and micro (discontinuum mechanics models) modeling. In macro modeling, masonry is assumed as a continuum homogenized model, usually, using finite element method. In this approach, the effect of mortar is considered implicitly. As a result, this practice oriented numerical approach does not consider the unit and mortar separately. Reasonable time and memory requirements are the leading features of macro modeling, which is applicable for large scale structures where the possible cracks can be smeared out. This numerical method makes sense when a compromise between accuracy and efficiency is needed (Lourenço 2002). In contrast to continuum models, in micro modeling, units and joint materials are represented separately so that masonry has potential crack and slip planes. The failure of masonry structures is generally controlled by the joints, where the interaction between units takes place in a nonlinear fashion. Hence, the main purpose of detailed micro modeling is to simulate the nonlinear behavior of masonry including all possible failure mechanisms. One of the first studies related with micro modeling dates back to the end of 1970s published by Page (1978). Then, Lourenço and Rots (1997) presented a sophisticated interface micro model, simulating nonlinear behavior of masonry and all possible failure mechanisms. Micro modeling is an appropriate approach for detailed analysis of small masonry models having a potential of large deformation, separation and sliding under given loading. The main drawback of this approach is that, due to high cost of micro modeling, it is mostly applicable to the analysis of masonry elements and not full structures, at least if each masonry unit is to be modelled individually.

There is another micro modeling approach, namely the discrete element method (DEM), that should provide an adequate representation of masonry depending on the number of contacts and complexity of the corresponding model. The nature of masonry is particularly suitable for this numerical modeling, initially developed by Cundall (1971). This numerical technique was first applied to jointed rock masses and then used in different fields, such as concrete, masonry and geo-materials. In case of masonry, units are taken into account as blocky elements and bond within the stone units or mortar, are represented by joints. In literature, there are only limited researches, related with the assessment of the seismic capacity of masonry walls using DEM, even if de Felice (2011) simulated rubble masonry walls using commercial software based on this technique. In this paper, different masonry wall cross sections were used, as well selected masonry structures, and their nonlinear response of masonry was successfully captured under static loading, thus further demonstrating the possibilities of the technique.

\section{Definition of constitutive laws}

Next, custom-made software, developed to perform nonlinear static and dynamic analysis by means of the discrete element method (Bretas et al. 2014) is used. Throughout the numerical procedure, the integration of the equations of motion for each degree of freedom is formulated and solved by using the central difference method iteratively. Furthermore, the static solutions are obtained by dynamic relaxation, using scaled masses and artificial damping. It is important to emphasize that the nonlinear response of masonry walls is simulated by taking the advantage of 
DEM, which is capable of modeling joint sliding and partial or total separation, in an explicit way.

This application adopts a face-to-face contact type in order to represent the joints, where the nonlinear reaction of the structure is governed. Thus, calculated stress values, located at the contact points, are controlled and updated in each iteration according to the properties of the joint material, using normal $\left(k_{n}\right)$ and tangential $\left(k_{s}\right)$ stiffness. A simple constitutive model for the joints in two perpendicular directions, namely normal and shear, is presented in Fig. 3. In normal direction, the elasto-plastic relation between normal stress $(\sigma)$ and displacement $\left(u_{n}\right)$ is limited by the compressive strength $\left(f_{c}\right)$ in compression and the tensile stress is set to zero after exceeding the given tensile strength $\left(f_{t}\right)$ at the contact point. As it can be noticed from Fig. 3(a), the tension capacity of the joints is set to a very low capacity and allows obtaining fragile behavior under tensile forces. The Mohr-Coulomb law is used for the shear stress $(\tau)$ as shown in stressdisplacement $\left(u_{s}\right)$ graph in Fig. 3(b). The constitutive relation is based on the cohesion $(c)$ and friction angle $(\phi)$ of the considered material.

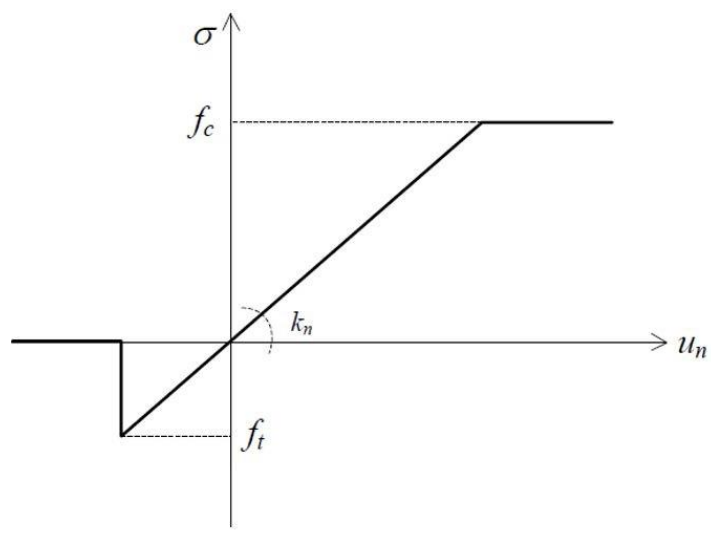

(a)

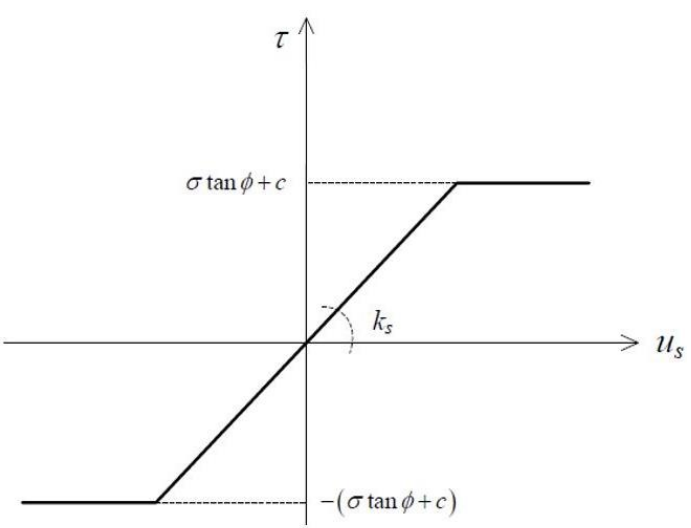

(b)

Fig. 3 Constitutive model at the joints: (a) in the normal direction and (b) in the tangential direction.

Hence, the constitutive laws mentioned above are applied to find out stress values at each step of the calculation. Furthermore, the adopted stress distribution, namely point model $(p t)$, for two contact points is presented in Fig. 4. Here, $f^{-}$and $f^{+}$indicate the resultant compression and tension forces, calculated from the area located below and above of the contact plane, respectively. Fig. 4(a) represents a contact in elastic domain and Fig. 4(b) shows the case of a contact with nonlinear stress distribution. However, it is clear that a low number of contacts may give results deviating from the correct force, due to the stress distribution in Fig. 4. Therefore, a sufficient number of contact points must be used in the analyses. 
Contact Model (pt)

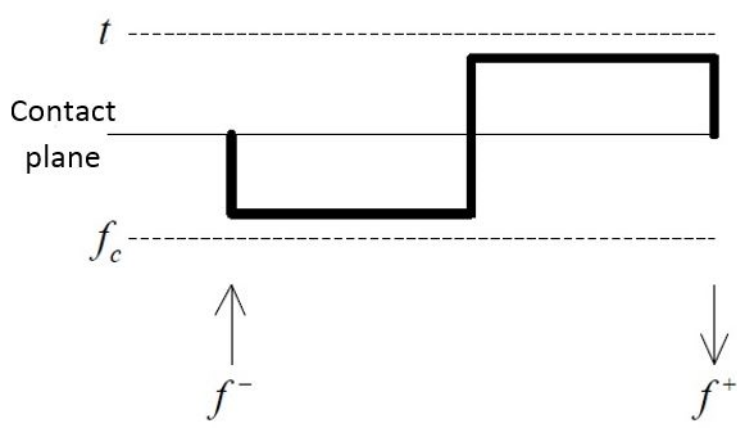

(a) No Rupture

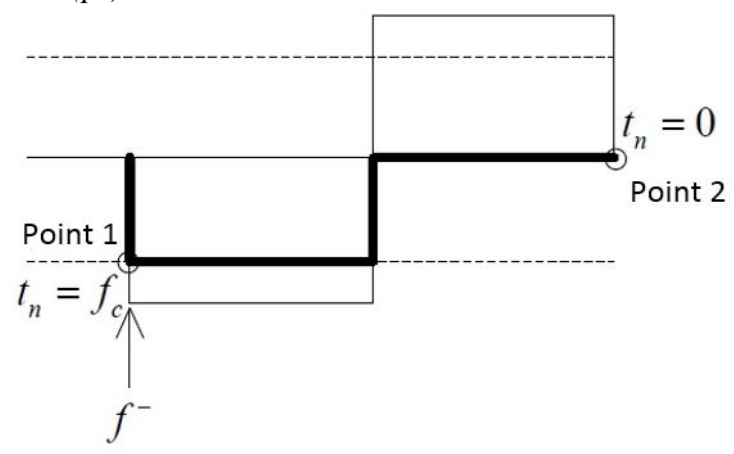

(b) Rupture

Fig. 4 Nonlinear stress distribution through the contact plane and resultant forces (Bretas et al. 2014).

\section{Simulation of masonry walls}

\subsection{Material Properties}

The composite nature of masonry makes it difficult to assign material properties, which depend on many factors (namely the masonry units and mortar). To be able to get realistic nonlinear behavior of masonry, the properties are selected next from recent studies and the European normative, namely EN 1996-1-1:2005 or Eurocode6 (2005), recommendations. There are two main sets of material properties needed for structural analysis, one for the stone units and the other for the joints. Stone is considered here for the masonry units with a density of 2.0 tons $/ \mathrm{m}^{3}$, elastic modulus of 20.0 GPa and Poisson's ratio of 0.2.

The vertical and horizontal stiffness of the joints are considered as $2.5 \mathrm{GPa} / \mathrm{m}$ and $1 \mathrm{GPa} / \mathrm{m}$, respectively (Lemos et al. 2011). The same contact properties are used for the interaction between foundation and masonry structures. The influence of tensile strength at the joints is considered by setting relatively low tensile capacity, $50 \mathrm{kPa}$. A friction angle of $37^{\circ}$ and cohesion of $75 \mathrm{kPa}$ were adopted. However, parametric analyses are also performed to observe the influence of tensile strength in out of plane strength and corresponding collapse mechanisms of masonry walls.

\subsection{Analytical validation}

To validate the custom-made software and assess the minimum number of contact points required for regular masonry walls, a simple loading scenario is adopted. In this particular case study, the maximum horizontal point load, acting on the top left corner of a stack bonded masonry section, is calculated by moment equilibrium. Hence, the maximum point load represented by red line in Fig. 5 is an analytical solution. The contact stiffness controls the elastic branch of the overall response, which does not a role in the strength capacity of the masonry wall.

It is necessary to note that there is a direct relationship between the stress distribution, or integrated forces acting on a particular contact plane, and the number of contacts. The results reveal that the horizontal load capacity converges to the static solution with an increase of the number of contact in the model. To obtain the correct static solution, stone units are meshed to 
have higher number of contact points, as given in Fig. 5. However, depending on the contact number, the computational cost may increase drastically. As a result of this, the number of contacts is selected based on a reasonable computational time and required level accuracy. In Fig. 5 , it is shown that after six contact points, the error in the solution gets lower than 10 percent, which seems reasonable for engineering applications. Therefore, a minimum of six contacts for each block is used in throughout the analyses. In case of rubble masonry, however, the number of contacts is not an issue, unlike stack bonded sections, due to high number of stone units and possible contact planes.

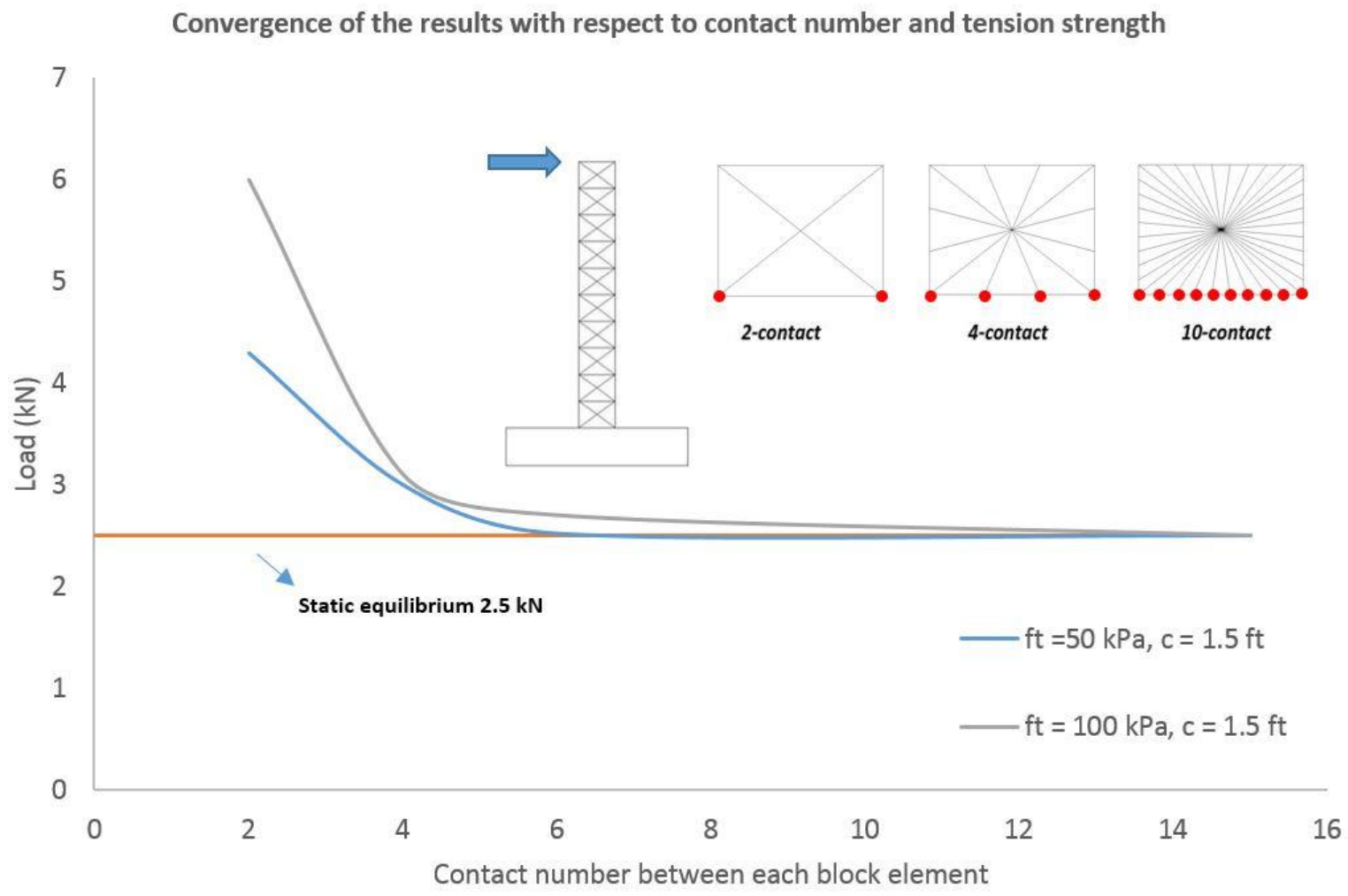

Fig. 5 Convergence curve according to the given number of contact and material properties, tensile strength and cohesion.

\subsection{Simulation of stack bonded masonry walls}

The main motivation in the present nonlinear analyses is to find out expected collapse mechanisms and possible damage conditions of masonry wall cross sections subjected to out of plane loading. First, contact forces due to self-weight of masonry wall are calculated and the corresponding stability condition is examined. Then, a horizontal acceleration, using a uniform pattern, proportional to the mass, is applied. The horizontal acceleration is increased step by step, until the wall fails. During the pushover analyses, the same material properties are used for all cross sections, whereas $50 \mathrm{kPa}$ tension and $75 \mathrm{kPa}$ cohesion strength are used for joints. As a result, 
identical rigid overturning mechanism, shown in Fig. 6, is obtained for all regular masonry cross sections. Although this would be unexpected for dry stone masonry, it is justified by the adopted tensile strength (typical of mortared masonry), which is sufficient to keep in contact the stone units.

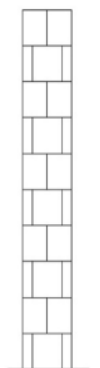

(a) Free standing

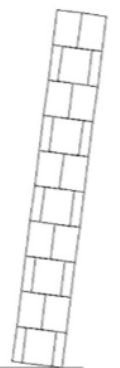

(b) Failure

Fig. 6 (a) Stack bonded wall (b) collapse mechanism of stack bonded masonry wall under uniform pushover.

In addition, to understand the influence of the geometrical composition of the units on displacement and collapse mechanism of stacked masonry walls, the capacity curve of different cross sections are plotted in a single graph, given in Fig. 7. The same maximum horizontal load is found as they have identical failure mechanisms. However, each cross section revealed different displacement capacities, as they have a different number of vertical joints based on their stone arrangements. Therefore, the morphology has an influence on energy dissipation and maximum displacement capacities.

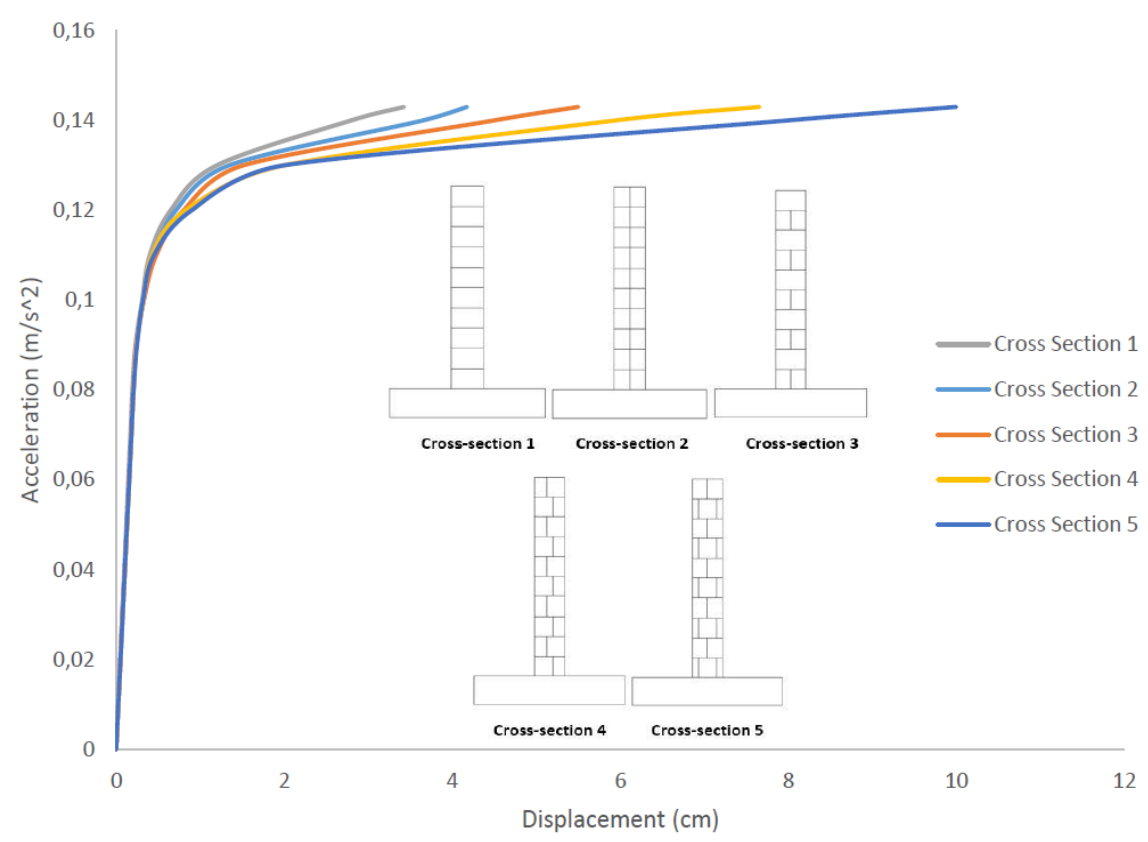

Fig. 7 Capacity curves for different cross section morphologies. 


\subsection{Parametric studies on masonry wall}

In masonry walls, the failure mechanism can partly change even if the capacity does not change significantly. Walls may provide different collapse mechanisms based on their material and geometrical properties. Unlike a rigid overturning failure, more sophisticated failure types may be observed such as large displacements within the stone units, sliding and separation of leaves. In many cases, highly nonlinear and heterogeneous nature of masonry provide more complex collapse mechanisms than a simple rigid overturning. To capture these mechanisms, the influence of contact properties is assessed by using zero tension and cohesion strengths as joint properties in stack bonded masonry walls in pushover analyses (dry stack masonry).

The rigid overturning mechanism is obtained only for the first cross section, composed of through stones, shown given in Fig. 8(a), although the displacement capacity has decreased when compared to walls with tensile strength. It is concluded that even without the presence of tensile capacity, a low number of joints and regular morphology of cross section may still result in monolithic behavior. In case of no connection between leaves, shown in Fig. 8(b), a drastic change in both failure mechanism and strength is found. The out of plane strength of second cross section (Fig. 8(b)) is obtained as half of the single leave cross section (Fig. 8(a)). This simulation shows that each single leave behaves independently, as presented by Giuffré (1989). In multiple leaves stack bonded cross sections, more complex collapse mechanisms can be obtained, as presented in Fig. 8(c)-(d). Different types of stone detachments, depending on the morphology of the sections, are noticed in the pushover analyses.

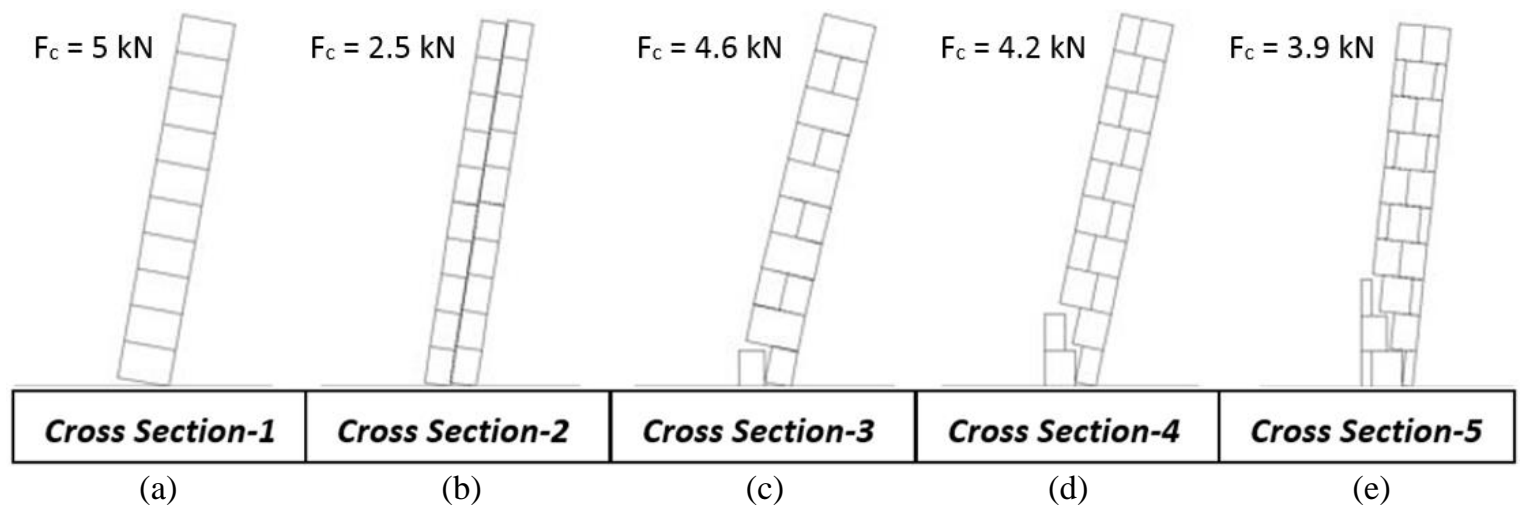

Fig. 8 Collapse mechanisms of stack bonded masonry walls, simulated under uniform pushover and corresponding Fc critical load (zero tensile and cohesion is adopted at the joints).

In Fig. 9, all capacity curves are given in the same graph. Less displacement capacity and lower out of plane strengths are found at the end of each analysis when compared to the masonry walls, mentioned of the previous section (with tensile and shear strength). A significant loss of strength can be noticed by comparing Fig. 7 and Fig. 9, especially in case of the second cross section, having separation between interior and exterior wall layers. 


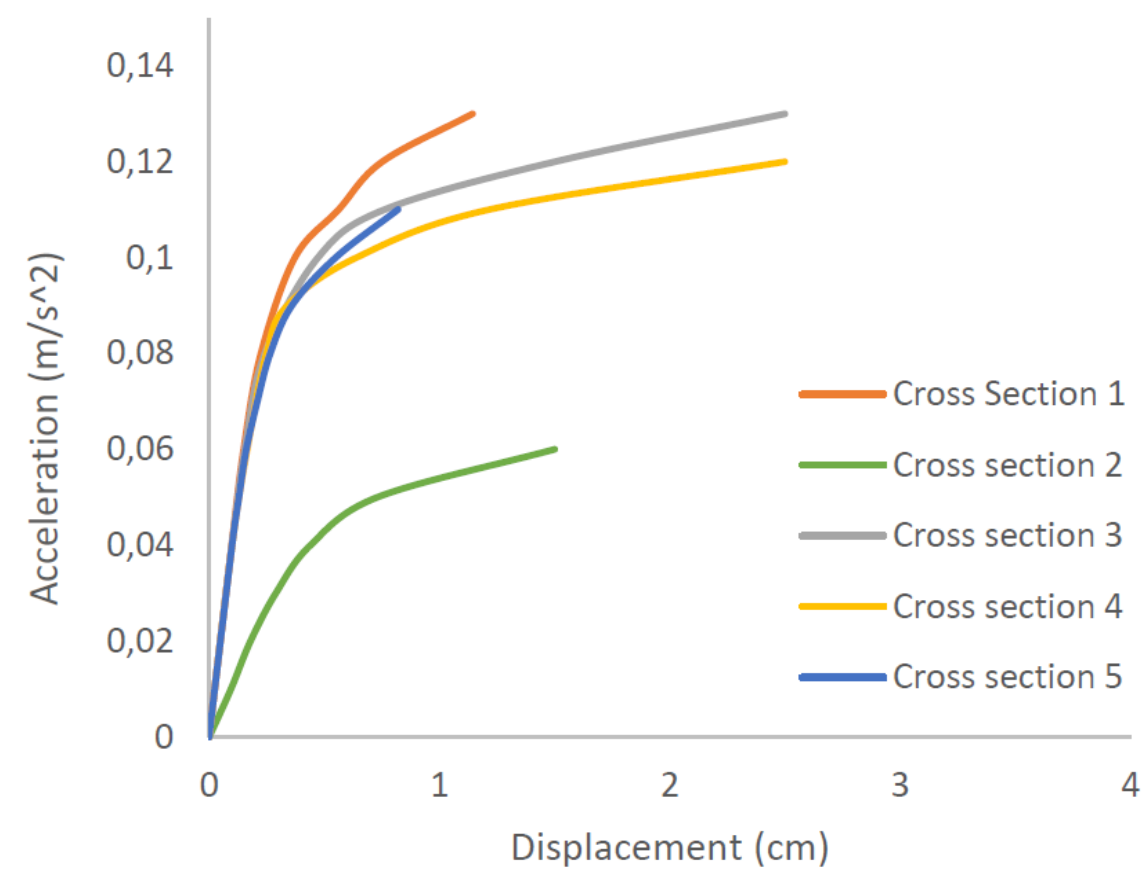

Fig. 9 Capacity curves of stack bonded walls, zero tensile and cohesion strengths at the joints.

\subsection{Single and double leave rubble masonry walls}

Nonlinear static analysis is applied to rubble masonry walls, using the same unit and joint properties as stack bonded walls. In case of irregular (or rubble) masonry, the collapse mechanisms are deeply related with the cross section morphologies. Hence, to examine the effect of through stones and geometrical composition of masonry, two different wall sections are proposed and analyzed using DEM.

The contribution, coming from geometrical properties of cross section to out of plane strength of masonry wall, is found out and the corresponding capacity curves are obtained. It is important to observe that irregular stone unit arrangements at the bottom part of cross section, given in Fig. 10 , causes a noticeable reduction in out of plane strength of masonry wall due to detachment of stone units, or loss of connection between blocks. Cross sections including through stones have higher capacity to keep contacts with other stone units by taking their geometrical advantages. As a result, mass participating in pushover analysis is higher for the cross section composed of only through stones and gives greater lateral load capacity. It is further demonstrated that the rotation point and amount of mass involved may change as a function of the cross section morphology and provided material properties. In order to transfer the horizontal load in transversal direction, through stones play an important role and have a necessary contribution to the out of plane performance of the masonry wall. 


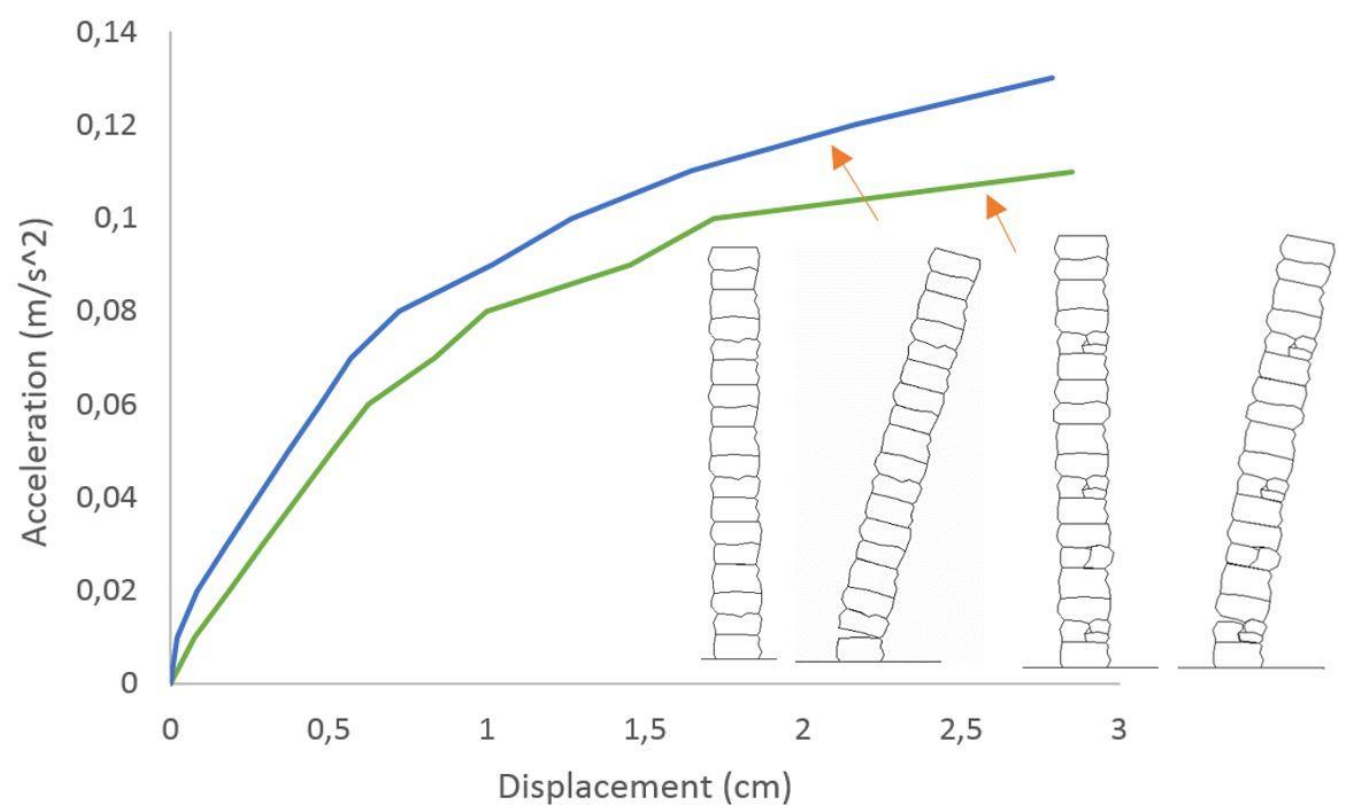

Fig. 10 Capacity curves of rubble walls, composed of different cross section morphologies.

To further extend the present study, more complex cross sections are prepared and analyzed using DEM. Different from single leave walls, $1 \mathrm{~m}$ thickness and $6 \mathrm{~m}$ height cross sections are considered to be closer to reality in multi-leaf walls. The capacity curve and collapse mechanism of the walls composed of small stone units and an inner core are presented in Fig. 11. It is observed that irregular geometry of wall cross section triggers the failure, which makes less predictable the collapse mechanism by hand calculation.
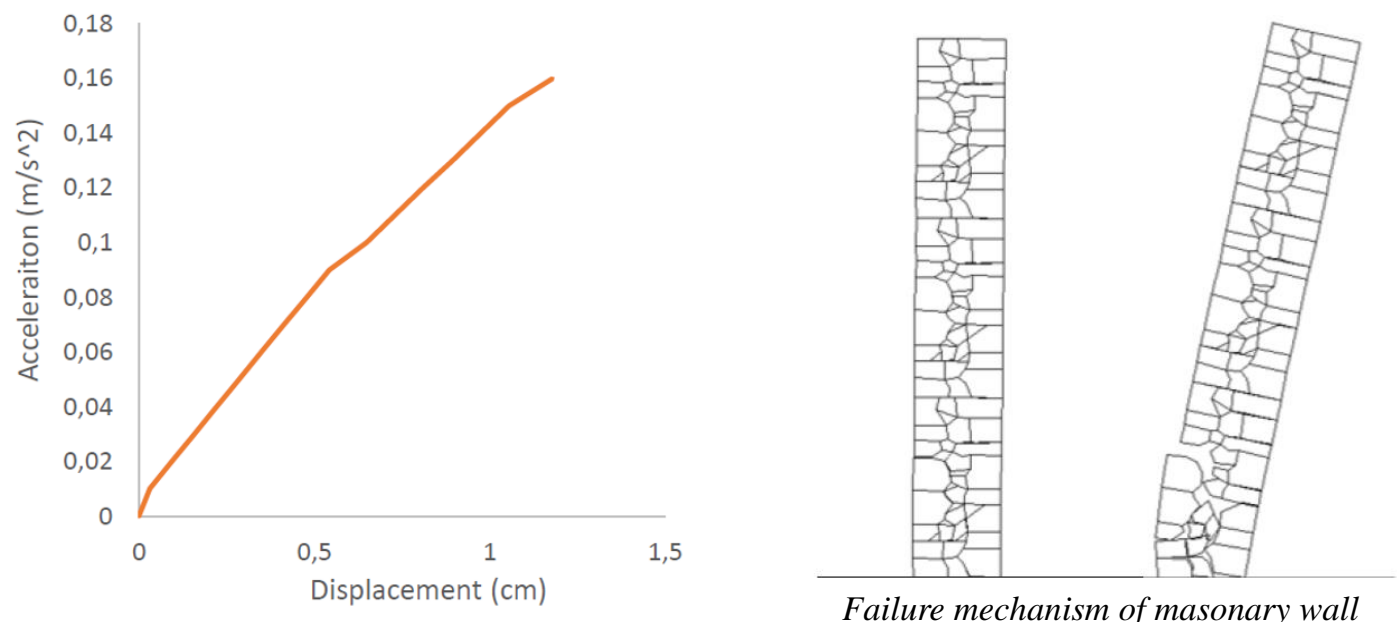

Fig. 11 Capacity curve of three-leave masonry wall cross section and collapse mechanism subjected to out of plane loading. 
The noticeable influence of geometry is examined on cross sections with larger dimensions, namely $2 \mathrm{~m}$ width and $12 \mathrm{~m}$ height, keeping the same aspect ratio. The separation through the inner part of the cross section, consisting of irregular and roughly squared stone units on either side of the wall, is given in Fig. 12, under uniformly distributed horizontal force. It is clearly observed that the collapse mechanism is governed by the quality of the inner material of rubble masonry. The irregular and poorly connected stone units are mainly responsible for the collapse of masonry wall (Sayin et. al. 2014). Cavities and lack of transversal connections cause separation, which can be partial or total, between inner and outer leaves as in the case of Fig. 12(a). Simulation of three leave rubble masonry walls with highly irregular stone units, low quality infill materials and poor workmanship cause severe stone detachments, or separation, as demonstrated in Fig. 12(a). However, adding a through stone to the cross section, at the width of the wall height from the ground level, see Fig. 12(b), may change the collapse and strength of wall section. Hence, the remarkable effect of through stone is demonstrated by the analysis. The separation is now observed at the middle height of section, unlike from the previous case. Therefore, separation of the inner and outer leaves in masonry can be prevented by using through stones or connectors passing through the wall cross section, as well known by builders of the past.

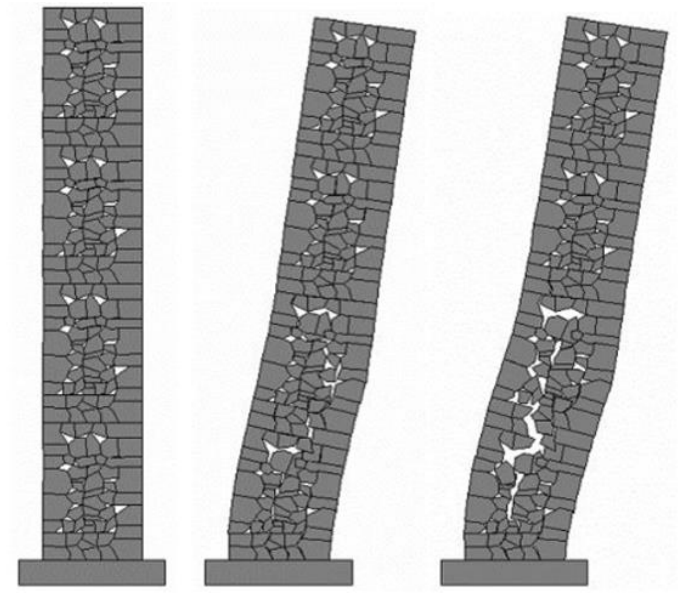

(a) Masonary wall without through stone

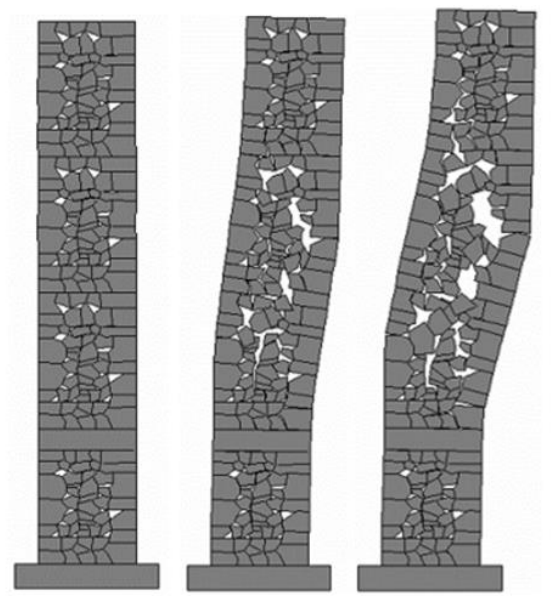

(b) Masonary wall with through stone

Fig. 12 Progression of the collapse mechanism under pushover analysis of three leave rubble masonry wall (a) without through stone and (b) with through stone.

In rubble masonry walls, it is particularly difficult to transfer the lateral loads without any connectors. The complex and irregular nature of masonry sections do not help to transfer the horizontal loads properly. The obvious difference between two proposed walls, in terms of strength and collapse mechanism, can be noticed in Fig. 13. The masonry walls, having through stone, presents 1.6 times higher capacity and higher deformation capacity. Therefore, connections and through stones are essential structural features to obtain adequate mechanical performance for rubble masonry walls subjected to out of plane loading. 


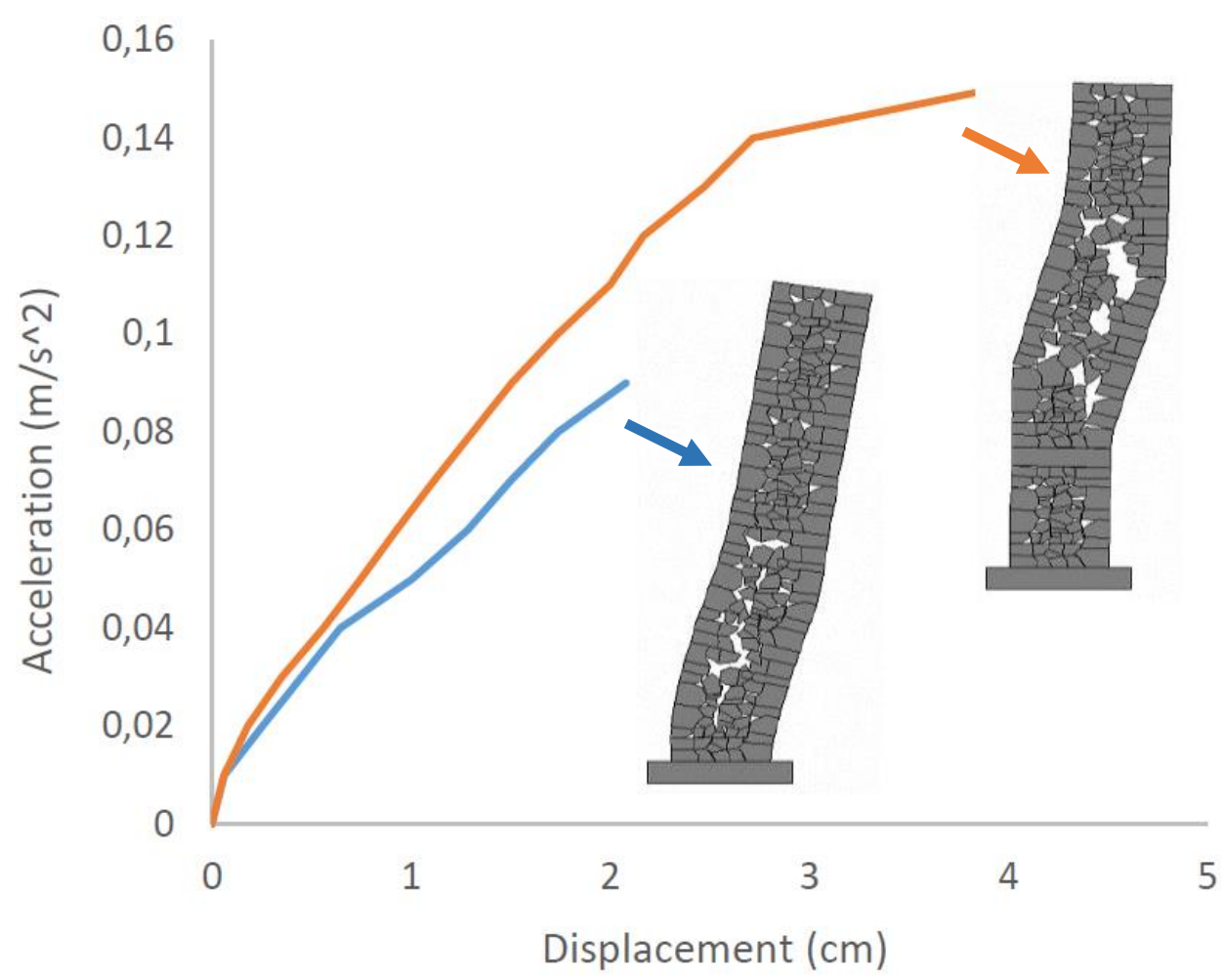

Fig. 13 Capacity curves of rubble masonry walls with and without through stone.

\section{Applications}

The preservation and strengthening of masonry structures against natural hazards is getting more popular and necessary research topic in structural engineering. However, the composite characteristics of masonry makes difficult to predict failure load and mechanism (Dogangun and Sezen 2010). In addition to the simulation of masonry walls, the possible collapse mechanisms and corresponding capacity curves of masonry structures with internal structure, such as portal frames, simple combinations of masonry piers and arches, and a historical tower, are examined under pushover analysis.

\subsection{Portal frames}

First, an isolated masonry wall cross section, which has a 1:5 B/H ratio, where $\mathrm{B}$ indicates the wall thickness and $\mathrm{H}$ is the wall height, is analyzed under pushover analysis. In this example, low tensile strength, $50 \mathrm{kPa}$, is considered for the joints to observe the possible stone detachments during the overturning, as given in Fig. 14. In case of historical masonry structures, mortar is not expected to have a considerable tensile strength. With time, bond existing within the stone units often loses its mechanical and physical properties due to progressive deterioration. As a result, detachments of stones, separation of external leaf and large displacements are the common type of failures under horizontal seismic forces. 


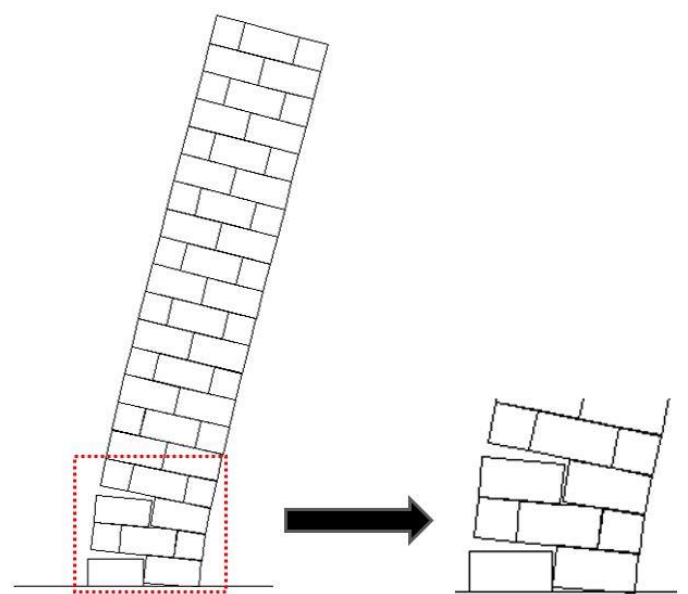

Fig. 14 Collapse mechanism of masonry wall under nonlinear static analysis using DEM.

Subsequently, the failure mechanism and maximum horizontal load capacity of the discrete element model of portal frames is compared with limit analysis based on the study of Giordano et al. (2007). In engineering practice, limit analysis is one of the common methods, especially for collapse of structural elements under lateral loading. The main hypotheses proposed by Heyman (1966) on mechanical behavior of masonry are used throughout these analyses: masonry has no tension capacity, infinite compression strength and no sliding failure. In addition, in case of the examined frames, Giordano et al. (2007) assumed that crack hinges can merely occur at the piers to spandrel connections, and pointed out six possible hinge locations, as shown in Fig. 15(a). However, four hinges are adequate to cause collapse mechanism that may occur by different hinge combination and kinematic chain. Giordano et al. (2007) analyzed a large number of kinematic mechanism and found the corresponding collapse multiplier of a horizontal concentrated force at the lintel in the presence of self-weight loads.

In the discrete element model of identical portal frame, the same connection and material properties are used. In this context, it is well known that the geometry of frames have a direct influence on minimum lateral force that causes failure. Thus, by changing the geometrical ratios, a parametric study is performed on the proposed structure. Three essential geometrical ratios, which are $\mathrm{B} / \mathrm{H}, \mathrm{H} / \mathrm{D}$ and $\mathrm{t} / \mathrm{H}$, are used during the analyses, as shown in Fig. 15(b). Here, $\mathrm{B}$ is the width of the pillar, $\mathrm{H}$ is the height of the portal, $\mathrm{D}$ is the width of the portal and $\mathrm{t}$ is the height of the beam. Hence, the effect of one geometrical ratio (B, D or t) is examined by fixing other two geometrical parameters. 


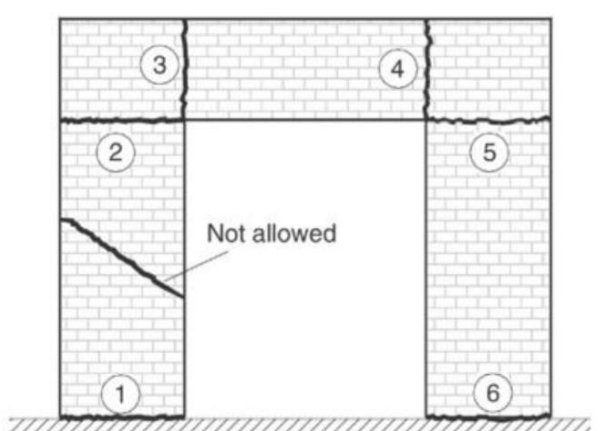

(a) Proposed crack pattern

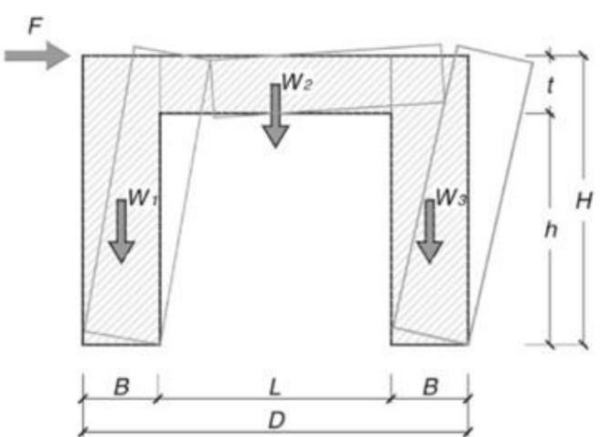

(b) Collapse mechanism

Fig. 15 (a) Possible crack pattern, no failure in blocks, (b) Failure mechanism that gives the minimum collapse multiplier as indicated by Giordano et al. (2007).

Good agreement between collapse simulation of discrete element model and limit analysis is found, as given in Fig. 16 for various $\mathrm{t} / \mathrm{H}$ values. It is important to note that the discrete element model gives the same results as limit analysis, as expected. Then, instead of eliminating the failure at the pillars, relatively small stone units, squared of $0.75 \mathrm{~m}$ width and $0.4 \mathrm{~m}$ height, are used at the piers, for a ratio of thickness to height of 1:7 as shown in Fig. 17. The main motivation was to observe the separation and detachment of stone units under pushover analysis. The clear span used is $4.5 \mathrm{~m}$ and the maximum tensile strength of the stone beam is assumed as $1 \mathrm{MPa}$.

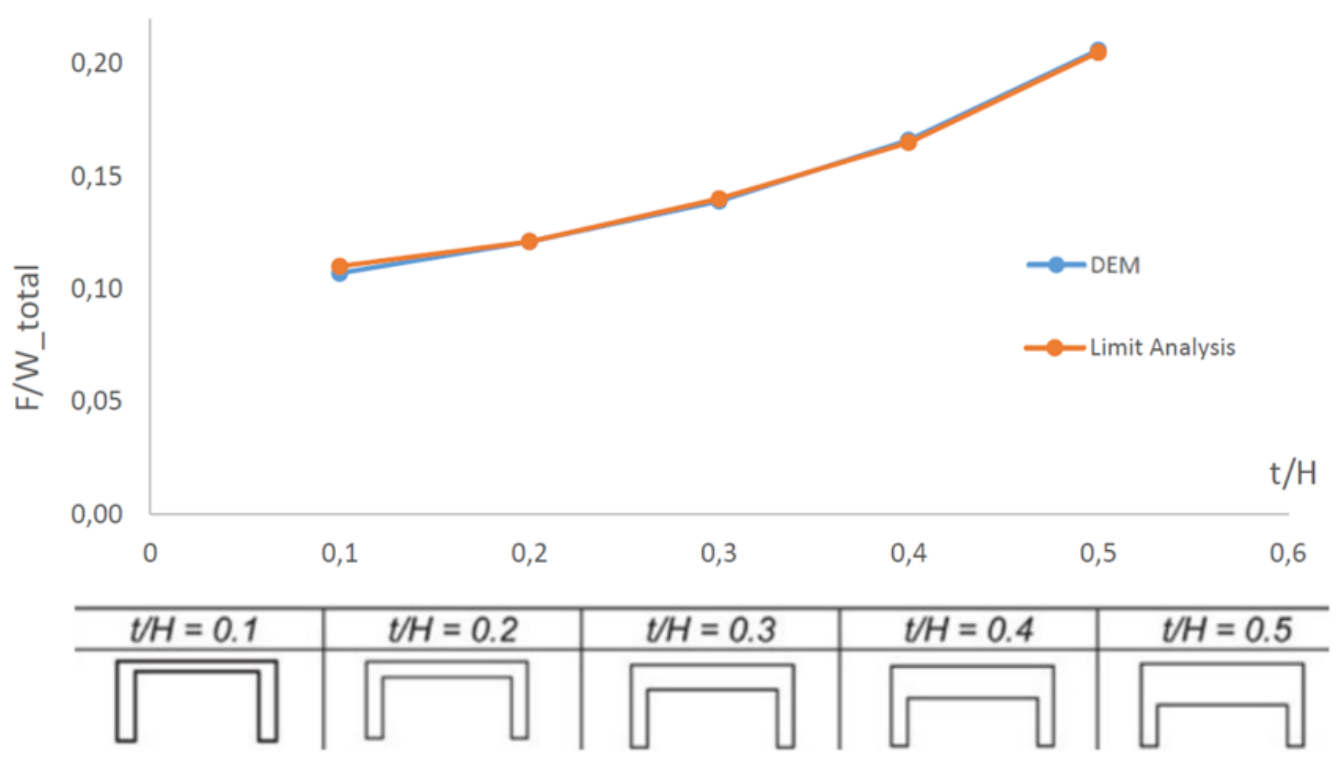

Fig. 16 Collapse multiplier for $\mathrm{B} / \mathrm{D}=0.1$ and corresponding results for limit and DEM analysis.

The tensile and cohesion strength, even if small, play some role in failure, which may influence the maximum horizontal load and displacement capacity. Therefore, two identical portal frames, 
with different tensile strength at their joints, are examined under pushover analysis. As shown in Fig. 17(a), the portal frame with a tensile capacity at the joint has less contact loss (stone detachment) and high structural integrity than the dry joint masonry frame. The difference can be recognized by looking at the Fig. 17(a) and Fig. 17(b) where minor failures and different hinge locations are highlighted by square boxed. The influence of joint properties in the response of the structure is further demonstrated in the next examples.

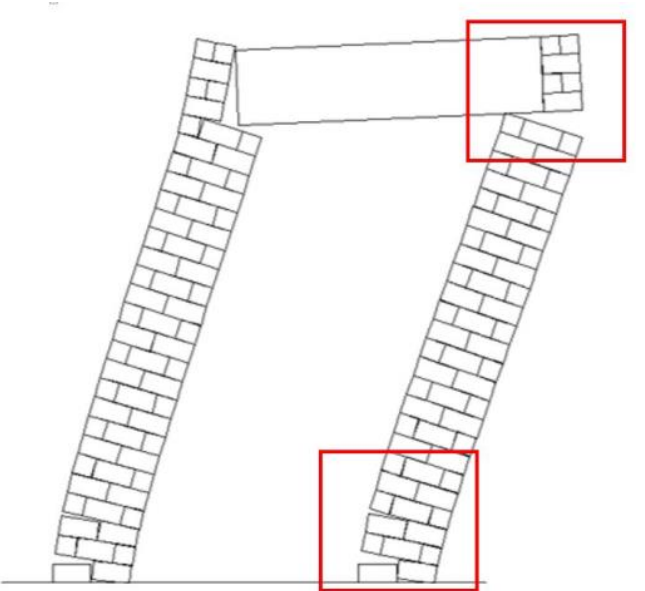

(a) $50 \mathrm{kPa}$ tensile strength at joints

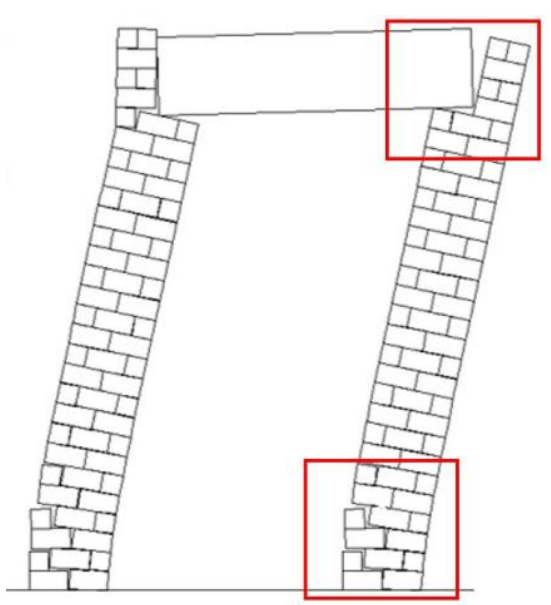

(b) Zero tensile strength at joints

Fig. 17 Failure mechanisms of masonry frames, simulated by using (a) $50 \mathrm{kPa}$ and (b) zero tension capacity at the joints.

\subsection{Simple combinations of masonry piers and arches}

The masonry column adopted in the previous section is used as a structural element in simple combinations with arches, including shallow, deep and gothic forms. These structures are again simulated to span $4.5 \mathrm{~m}$ opening. Difference between displacement and lateral force capacities of masonry structures having the same pier height and span is then discussed.

Masonry arches have a long history that dates back to several thousand years. However, they were built mostly based on proportionality concepts, by experience and "rules of thumb" (Brencich and Morbiducci 2007). As a result, shallow and deep arches, having 0.1 and 0.5 relative depths, which is the ratio between rise and span, are considered here, as shown in Fig. 18. The largest rise is used for the point (gothic) arch. Then, the arch thickness is calculated according to the formula given in the National Technical Code of Italy, see (Brencich and Morbiducci 2007). It is stressed that, in literature, there are enormous number of empirical approaches to calculate the possible thickness of an arch. 


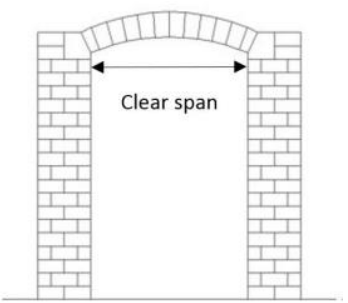

(a)

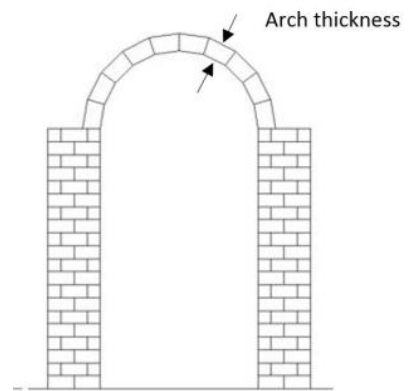

(b)

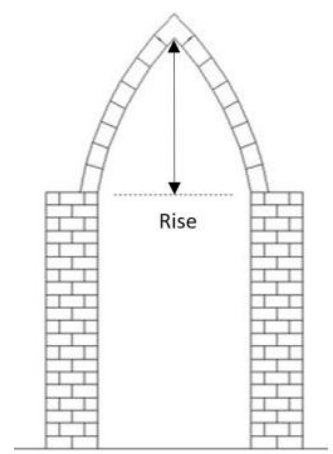

(c)

Fig. 18 (a) Pier and shallow arch, (b) pier and deep arch, (c) pier and point (gothic) arch.

In all analyzed structures, the top left and right corners of the piers are selected as monitoring points in the DEM analyses. Among the pier arches, the shallow arch could not withstand any high horizontal thrust force, with the proposed geometry. The collapse mechanism of discrete element models are given in Fig. 19. First, deflected shapes under self-weight is obtained. Then, gradually increasing uniform horizontal load is applied until the maximum lateral load and corresponding failure mechanism. While the top part of the point arch shows separation from the original geometry, the other pier arches exhibit hinge mechanism as given in Fig. 19.

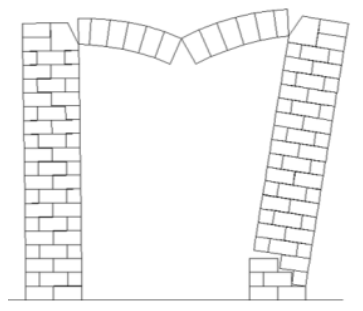

(a)

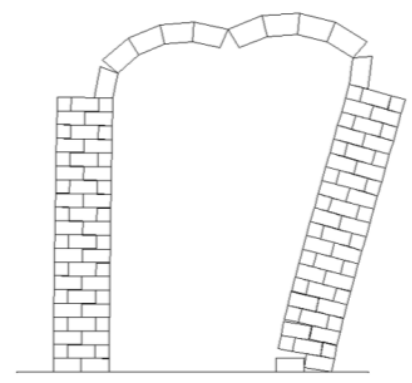

(b)

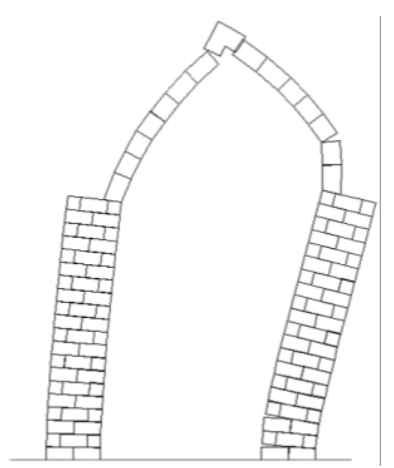

(c)

Fig. 19 Collapse mechanism of different masonry structures under pushover analysis: (a) pier and shallow arch, (b) pier and deep arch, (c) pier and point arch.

The capacity curves of individually examined masonry structures are given in a single plot by Fig. 20. It has been already emphasized that there are several parameters which influence the horizontal load capacity of masonry walls, frames and arches. Thus, in order to compare the simulated discrete element models, identical geometrical parameters are used for portal frame and pier arch models. In the case of portal frames, the horizontal beam has a significant influence on lateral load capacity of structure, as two walls work together and some double curvature effect is found under nonlinear static analysis. Hence, the frame effect is beneficial to the response. On the other hand, masonry arches have a detrimental effect on the capacity of the columns in terms of 
horizontal load resistance, as shown in the figure. The main reason is the thrust applied to the walls under self-weight of the arch. Therefore, different capacity curves are obtained for similar geometry of walls, depending on the type of masonry structure spanning between the walls.
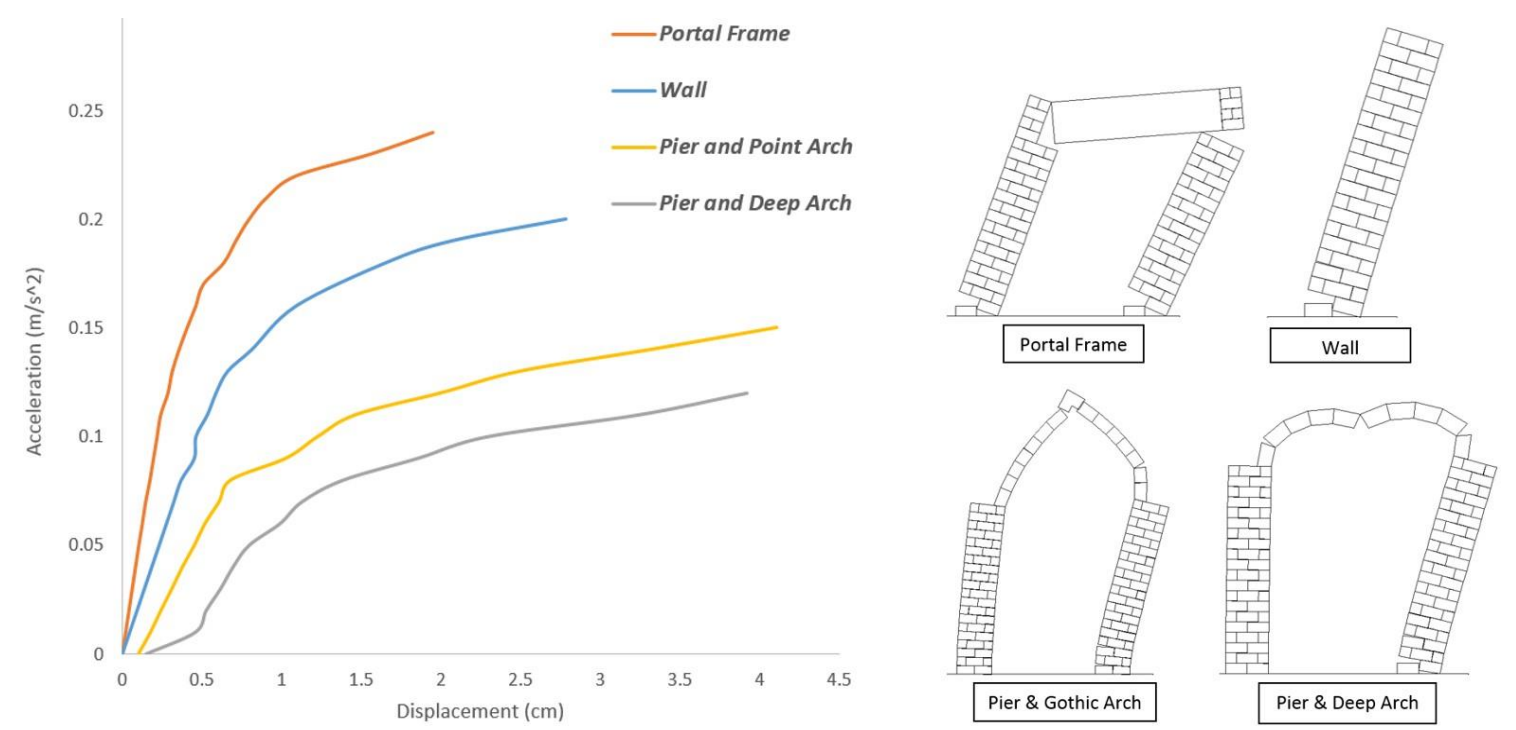

Fig. 20 Capacity curves of analyzed masonry structures.

\subsection{Masonry tower}

Finally, a tall historical masonry tower, namely the Qutb Minar in New Delhi, India, is analyzed by the custom-made DEM application. There is a comprehensive numerical model of the Qutb Minar, published by Pena et al. (2010). However, discrete element modeling of this tower, presented here, not only makes a contribution to previous studies but also validates DEM to analyze masonry structures.

The Qutb Minar, an example of a typical Indo Islamic architecture, is one of the most important monument in India. The minaret has 5 stories and at the each story there exists a balcony, as given in Fig. 21(a). Through the long history of Qutb Minar, there are several restoration and strengthening works had been carried out. The simplified geometry of the minaret can be considered as roughly circular, having a base diameter of $14.07 \mathrm{~m}$ and tapering to a diameter of $3.0 \mathrm{~m}$ at the top, with a total height of $72.5 \mathrm{~m}$ (Pena et al. 2010).

The recent research, performed by University of Minho, to assess the seismic performance of Qutb Minar includes structural survey, dynamic identification and numerical analysis. There are three different numerical models that were considered by researchers. Two of them use the Finite Element Method (FEM), one uses 3-D solid elements while the other was performed with 3-D composite beams, and the third model uses 2D in-plane elements based on Rigid Element Method (REM) (Pena et al. 2010). Here, a 2D discrete element model of the masonry tower, comprising of 39 blocks and 113 contacts, is presented and the capacity curve is obtained.

First, the complex geometry of the minaret is simplified by taking into account the previous work and the required level of accuracy from the nonlinear static analysis, as shown in Fig. 21(b). 
A constitutive law, simple elasto-plastic relation in compression and linear tension without softening, is considered in the discrete element model. For the tension and cohesion strength, $50 \mathrm{kPa}$ and $75 \mathrm{kPa}$ are used, respectively. In addition, two different material properties are assigned to the numerical model. The reason is that the last two stories were built in a later period and the adopted stones are different from the other stories, according to the structural survey, as given in Table 1.

Table 1 Material properties for the DEM model

\begin{tabular}{|c|c|c|c|}
\hline Block properties & $\begin{array}{c}\text { Elastic modulus } \\
(\mathrm{GPa})\end{array}$ & $\begin{array}{c}\text { Specific mass } \\
\left(\mathrm{kg} / \mathrm{m}^{3}\right)\end{array}$ & $\begin{array}{c}\text { Poisson's } \\
\text { coefficient }\end{array}$ \\
\hline Story 1-3 & 3.18 & 1900 & 0.2 \\
\hline Story 4-5 & 0.57 & 1900 & 0.2 \\
\hline Joint properties & $\mathrm{K}_{\mathrm{n}}(\mathrm{kPa})$ & $\mathrm{K}_{\mathrm{s}}(\mathrm{kPa})$ & Friction angle $\left(^{\circ}\right)$ \\
\hline Story 1-3 & $6.0 \mathrm{E}+06$ & $2.5 \mathrm{E}+06$ & 37 \\
\hline Story 4-5 & $1.5 \mathrm{E}+06$ & $6.0 \mathrm{E}+05$ & 37 \\
\hline
\end{tabular}

The nonlinear static analysis of masonry tower is performed as follows: after gravitational acceleration is given, an increasing acceleration, proportional to the mass of structure, is applied in a uniform pattern. Therefore, at the end, the maximum lateral force and corresponding failure at the bottom part of the tower is found, as shown in Fig. 21(c).

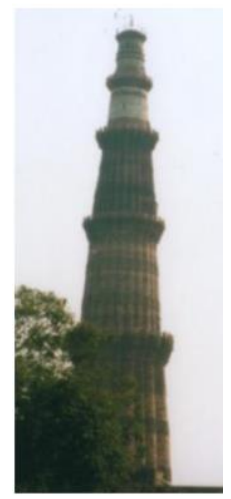

(a)

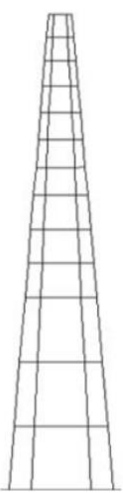

(b)

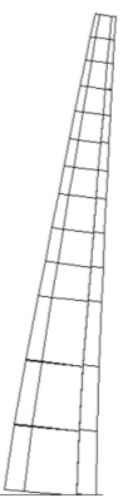

(c)

Fig. 21 (a) Qutb Minar, New Delhi (b) Discrete element model of the minaret (c) Collapse mechanism under pushover analysis.

As may be noticed in Fig. 22, various capacity curves, based on four different numerical models are given, in terms of load factor $\lambda$ (base shear/self-weight) vs. top displacement (in meters). Each simulation indicates the same failure mechanism and relatively similar capacity curves. The discrete element approach gives also compatible results and identical rigid overturning failure where the maximum moment exists. It is noteworthy to emphasize that, dynamic analysis, 
explained in detail Pena et al. (2010), exhibits failure at the top of the Minaret, unlike pushover analyses. Therefore, the higher modes influence the collapse mechanism that pushover analysis does not consider. Still, the present analysis further validates the adopted DEM code and shows good agreement with other numerical approaches obtained by pushover analysis.

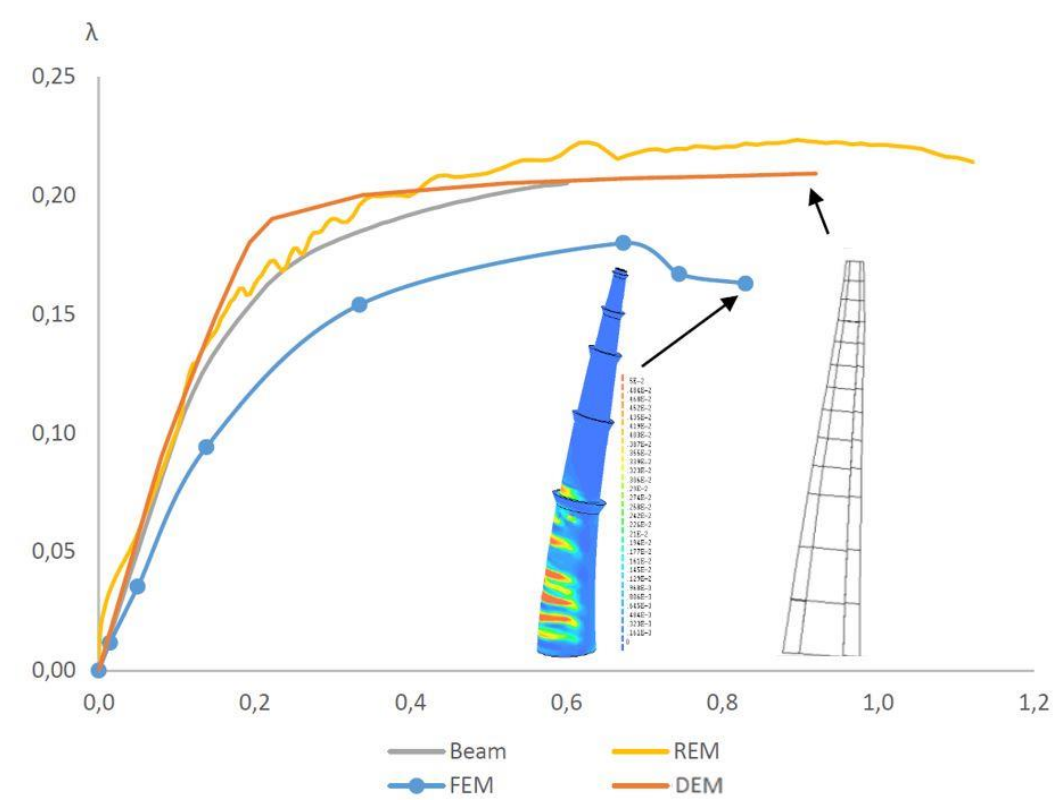

Fig. 22 Capacity curves of Qutb Minar obtained by different numerical approaches.

\section{Conclusion}

Simulation of masonry structures does not have a straightforward or unified approach. Various numerical approaches may be applied depending on the required level of accuracy and computational cost. This paper mainly addresses the simulation of masonry walls, portal frames, simple combinations of masonry piers and arches, and a historical masonry tower under static lateral loading. The complex and nonlinear behavior of masonry is modeled using the discrete element method. Realistic failure mechanisms and maximum lateral load capacities are found for the discontinuum idealization of the examined structures.

The numerical analysis of stack bonded masonry walls shows that the morphology of the cross section have a significant role in displacement and horizontal load capacity. The poor workmanship and low quality infills make difficult to predict the exact collapse mechanism due to uncertainties in stress distribution within irregular stone units. However, the need of through stones to obtain monolithic behavior is obvious, as found using DEM.

The influence of joint properties is revealed for two-leave stack bonded section in which there is no connection between interior and exterior leafs. The lack of cohesion and appropriate bond between stone units cause separation and detachment of stone blocks from wall cross section. Therefore, adequate cohesion and tensile strength, which can be provided by grouting or stitching, is essential to get good out of plane capacity under lateral loading. 
The structural performance of the wall cross sections are further examined as a structural element in portal frames and pier arches. In case of portal frames, a remarkable increment in horizontal load capacity is observed, compared to the single wall cross section, due to the frame effect. On the other hand, deep, shallow and point arches presented lower capacities due to thrust force under gravity loading.

Finally, the custom-made discrete element code is validated comparing the results obtained with other numerical models. Good agreement between various numerical approaches is found for an old masonry tower, with similar collapse mechanisms. As a result, it is further demonstrated that DEM is a powerful numerical technique to perform structural analyses of masonry structures in the non-linear range.

\section{References}

Asteris, P.G., Sarhosis V., Mohebkhah A., Plevris, V., Papaloziou, L., Komodromos, P. and Lemos, J.V. (2015), Handbook of Research on Seismic Assessment and Rehabilitation of Historical Structures. Numerical Modeling of Historical Masonry Structures, Engineering Science Reference, Pennsylvania, PA, USA.

Binda, L., Saisi, A. and Tiraboschi, C. (2000), "Investigation procedures for the diagnosis of historic masonries", Constr. Build. Mater., 14(4), 199-233.

Binda, L., Cardani, G. and Saisi, A. (2005), "A classification of structures and masonries for the adequate choice of repair", Proceedings of the International RILEM Workshop Repair Mortars for Historic Masonry, Delft, Netherlands, January.

Brencich, A. and Morbiducci, R. (2007), "Masonry arches: historical rules and modern mechanics", Int. J. Archit. Herit., 1(2), 165-189.

Bretas, E.M., Lemos, J.V. and Lourenço, P.B. (2014), "A DEM based tool for the safety analysis of masonry gravity dams", Eng. Struct., 59, 248-260.

Cundall, P.A. (1971), "A computer model for simulating progressive large scale movements in block rock systems", Proceedings of the International Symposium on Rock Mechanics, Nancy, France, September.

de Felice, G. (2011), "Out of plane seismic capacity of masonry depending on wall section morphology", Int. J. Archit. Herit., 5(4-5), 466-482.

Dogangun, A. and Sezen, H. (2012), "Seismic vulnerability and preservation of historical masonry monumental structures", Earthquakes Struct., 3(1), 83-95.

Eurocode 6 (2005), Design of masonry structures - Part 1-1: General rules for reinforced and unreinforced masonry structures, European Committee for Standardization, Brussels.

Ferreira, T.M., Costa, A.A. and Costa, A. (2014), "Analysis of the out of plane seismic behavior of unreinforced masonry: A literature review”, Int. J. Archit. Herit., DOI: 10.1080/15583058.2014.885996.

Giamundo, V., Sarhosis, V., Lignola, G.P., Sheng Y. and Manfredi, G. (2014), "Evaluation of different computational modeling strategies for the analysis of low strength masonry structures", Eng. Struct., 73, 160-169.

Giordano, A., De Luca, A., Mele, E., and Romano, A. (2007), "A simple formula for predicting the horizontal capacity of masonry portal frames", Eng. Struct., 29(9), 2109-2123.

Giuffré, A. (1989), "Mechanics of Historical Masonry and Strengthening Criteria", XV Regional Seminar on Earthquake Engineering, Ravello, Italy

Heyman, J. (1966), “The stone skeleton”, Int. J. Solids Struct., 2(2), 249-279.

Isfeld, A. and Shrive, N. (2015), "Discrete element modeling of stone masonry walls with varying core conditions: Prince of Wales fort case study", Int. J. Archit. Herit., 9(5), 564-580.

Krawinkler, H. (1996), "Pushover analysis: why, how, when and when not to use it", Proceedings of the $65^{\text {th }}$ Annual Convention of the Structural Engineers Association of California, Maui, Hawaii, October. 
Lemos, J.V. (2007), "Discrete element modeling of masonry structures”, Int. J. Archit. Herit., 1(2), 190-213. Lemos, J.V., Costa, A.C. and Bretas E.M. (2011), Assessment of the Seismic Capacity of Stone Masonry Walls with Block Models, In: Computational Methods in Earthquake Engineering, Springer, Netherlands.

Lourenço, P.B. and Rots, J.G. (1997), "Multisurface interface model for analysis of masonry structures", $J$. Eng. Mech. ASCE, 123(7), 660-668.

Lourenço, P.B. (2002), "Computations of historical masonry constructions", Prog. Struct. Eng. Mater., 4(3), 301-319.

Lourenço, P.B. (2009), Recent Advances in Masonry Structures: Micro-Modelling and Homogenisation, In: Multiscale Modeling in Solid Mechanics: Computational Approaches, Imperial College Press, London, UK.

Page, A.W. (1978), "Finite element model for masonry", J. Struct. Div. ASCE, 104(8), 1267-1285.

Pena, F., Lourenço, P.B., Mendes, N. and Oliveira, D.V. (2010), "Numerical models for the seismic assessment of an old masonry tower", Eng. Struct., 32(5), 1466-1478.

Roca, P., Cervera, M., Gariup G. and Pela, L. (2010), "Structural Analysis of Masonry Historical Constructions. Classical and Advanced Approaches", Arch. Comput. Meth. Eng., 17(3), 299-325.

Sayın, E., Yön, B., Calayır, Y. and Gör, M. (2014), "Construction failures of masonry and adobe buildings during the 2011 Van earthquakes in Turkey", Struct. Eng. Mech., 51(3), 503-518. 